\title{
The Structure of Ribbon Borides in a Ti-44Al-4Nb-4Zr-1B Alloy
}

\author{
U. Kitkamthorn*, L. C. Zhang*, T. T. Aindow $\ddagger$ and M. Aindow*
}

*Department of Materials Science and Engineering, Institute of Materials Science, Unit 3136, University of Connecticut, Storrs, CT 06269-3136, USA.

\$ Engine Control Systems, Hamilton Sundstrand, Windsor Locks, CT 06096-1010, USA.

There has been considerable interest in the addition of beta-stabilizing elements, such as $\mathrm{Nb}$ and $\mathrm{Zr}$ to titanium aluminide alloys because the beta phase imparts improved ductility and toughness [1]. The alloys are typically produced by casting, and to retain high strength it is imperative to refine the as-cast grain structure. This is typically achieved by the addition of $\mathrm{B}$, but there is still some controversy about the refinement mechanism. In our work we are attempting to address this issue by studying the morphology and microstructure of the borides in the as-cast alloys.

The borides in an as-cast sample of Ti-44Al-4Nb-4Zr-1B (atomic \%) were investigated using SEM and TEM. Samples for SEM were prepared by deep electrolytic etching using $7 \mathrm{vol} \% \mathrm{HCl}$ in methanol at 20V DC for 20-30 s. TEM samples were prepared by twin-jet electropolishing to perforation using an electrolyte of $6 \%$ perchloric acid, $34 \%$ butanol and $60 \%$ methanol at $-15^{\circ} \mathrm{C}$ and $25 \mathrm{~V}$. The samples were then ion-milled to ameliorate the effects of differential thinning and to remove any contamination from the surfaces. CTEM experiments were performed using a Philips EM420 operating at $100 \mathrm{kV}$ whereas HRTEM lattice images were acquired using JEOL 2010 FasTEM equipped with a UHR objective lens polepiece $\left(\mathrm{C}_{\mathrm{s}} \approx 0.5 \mathrm{~mm}\right)$ and operated at $200 \mathrm{kV}$.

SEM micrographs such as Fig. 1 revealed that most of borides are ribbon-like. The apparent volume fraction of the borides was higher than expected from the B content because the ribbons consist of thin flakes or plates of boride phases interleaved with thin layers of metallic phases as revealed in BF-TEM images (Fig. 2). The dominant phase in the boride plates is TiB with the $\mathrm{B}_{\mathrm{f}}$ structure. HRTEM images such as Fig. 3 showed that the thin metallic layers exhibit the ordered B2 structure. Within the boride plates, planar faults were observed which correspond to monolayers of $\mathrm{Ti}_{3} \mathrm{~B}_{4}$ intergrown with the $\mathrm{B}_{\mathrm{f}}$ phase along [010]. Thin embedded slabs of $\mathrm{TiB}_{2}$ were also observed in some of the boride plates. These phases adopt well-defined orientation relationships given by [001]TiB- $\mathrm{B}_{\mathrm{f}}$ $/ /[001] \mathrm{Ti}_{3} \mathrm{~B}_{4} / /[1210] \mathrm{TiB}_{2} / /<010>\mathrm{B} 2$ or $[100] \mathrm{TiB}-\mathrm{B}_{\mathrm{f}} / /[100] \mathrm{Ti}_{3} \mathrm{~B}_{4} / /[0001] \mathrm{TiB}_{2} / /<100>\mathrm{B} 2$ and (010)TiB- $\mathrm{B}_{\mathrm{f}} / /(010) \mathrm{Ti}_{3} \mathrm{~B}_{4} / /(10 \overline{0} 0) \mathrm{TiB}_{2} / /\{001\} \mathrm{B} 2$. Occasional thin layers with the B27 structure were also found parallel to $\{110\} \mathrm{B}_{\mathrm{f}}$ with the relationship: [010]B27//[001] $\mathrm{B}_{\mathrm{f}}$ and $(100) \mathrm{B} 27 / /(110) \mathrm{B}_{\mathrm{f}}$. We note that the four structures $\mathrm{TiB}-\mathrm{B} 27$, $\mathrm{TiB}-\mathrm{Bf}, \mathrm{Ti}_{3} \mathrm{~B}_{4}$, and $\mathrm{TiB}_{2}$ all contain the same structural unit, namely trigonal prisms with $\mathrm{Ti}$ atoms at the corners and a $\mathrm{B}$ atom at the center. $\mathrm{The}_{\mathrm{f}}, \mathrm{Ti}_{3} \mathrm{~B}_{4}$ and $\mathrm{TiB}_{2}$ structures correspond to sheets of these prisms with different stacking sequences (Fig. 4) and hence $\mathrm{Ti}_{3} \mathrm{~B}_{4}$ and $\mathrm{TiB}_{2}$ can form as coherent intergrowths on the (010) plane of $\mathrm{TiB}-\mathrm{B}_{\mathrm{f}}$ whereas the intergrowth of $\mathrm{Ti}_{3} \mathrm{~B}_{4}$ or $\mathrm{TiB}_{2}$ in TiB-B27 is not favorable due to the large interfacial misfit [2]. This indicates that even though TiB- $\mathrm{B}_{\mathrm{f}}$ is not a stable phase in the binary Ti-B system, it may be the preferred monoboride phase when the solidification path favors the formation of $\mathrm{Ti}_{3} \mathrm{~B}_{4}$ and/or $\mathrm{TiB}_{2}$. For the alloy studied here the primary phase formed upon solidification is $\beta$-Ti. During the growth of this phase, all of the B atoms are rejected into the liquid metal due to the very low solubility of boron in $\beta$-Ti. The boron-enriched liquid ahead of the solidification front results in a large degree of 
supercooling, and renucleation of $\beta$-Ti occurs [3]. The ribbon borides develop as thin plates due to rapid growth along [001] $\mathrm{B}_{\mathrm{f}}$ and $[100] \mathrm{B}_{\mathrm{f}}$ following nucleation. This gives severe local depletion in $\mathrm{B}$ leading to the formation of alternating boride and metal layers within the ribbons.

\section{References}

[1] T.T Cheng and M.H. Loretto, Acta Mater 46 (1998) 4801.

[2] M. De Graef, J.P.A. Löfvander, C. McCullough and C.G. Levi, Acta Metall Mater 40 (1992) 3395.

[3] T.T Cheng, Intermetallics 8 (1999) 29.

[4] This work is supported by National Science Foundation, USA and the Royal Thai Government.

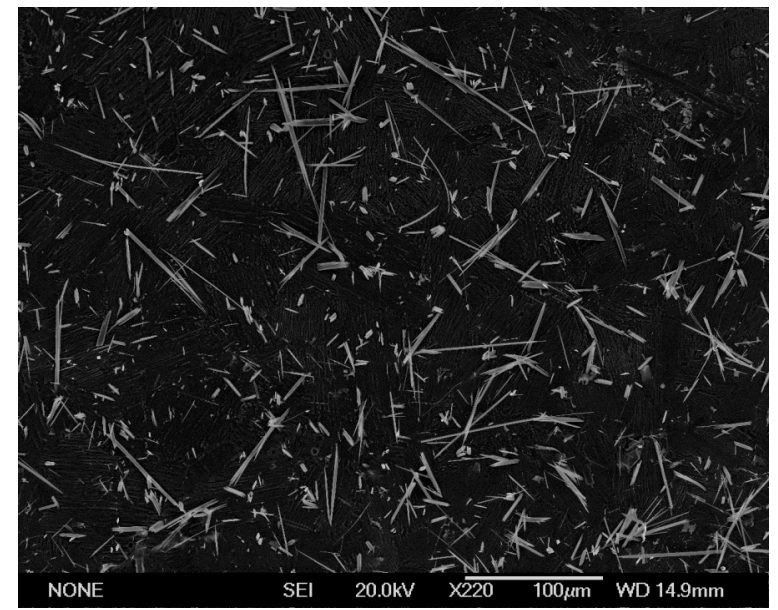

Figure 1 SEM micrograph showing ribbon borides in the as-cast Ti-44Al-4Nb-4Zr-1B.

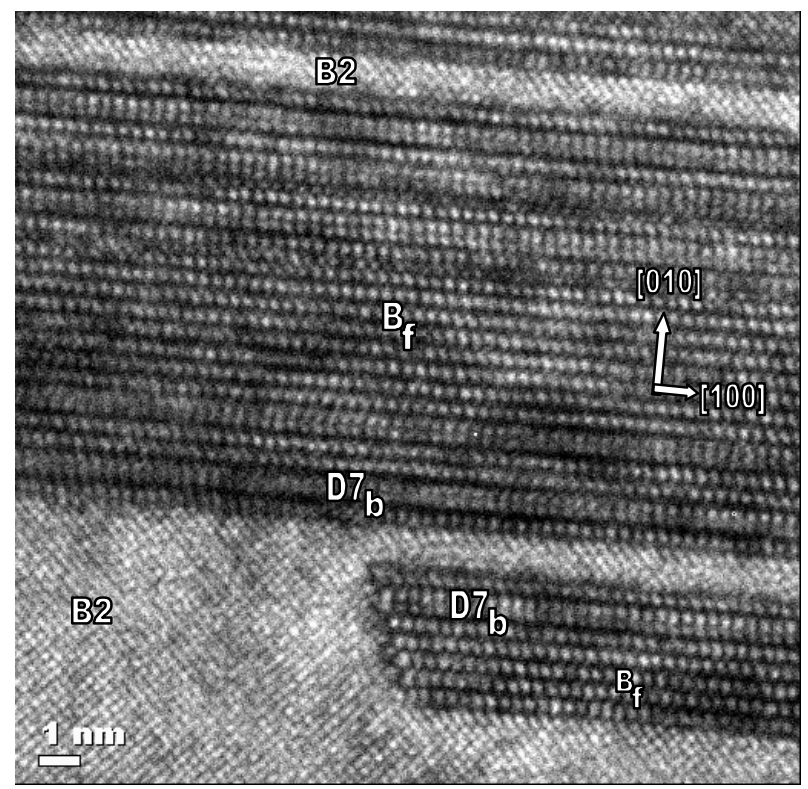

Figure 3 HRTEM image showing intergrowth between $\mathrm{TiB}-\mathrm{B}_{\mathrm{f}}$ and $\mathrm{Ti}_{3} \mathrm{~B}_{4}$. The metallic phase between and around the boride plates exhibits the ordered B2 structure.

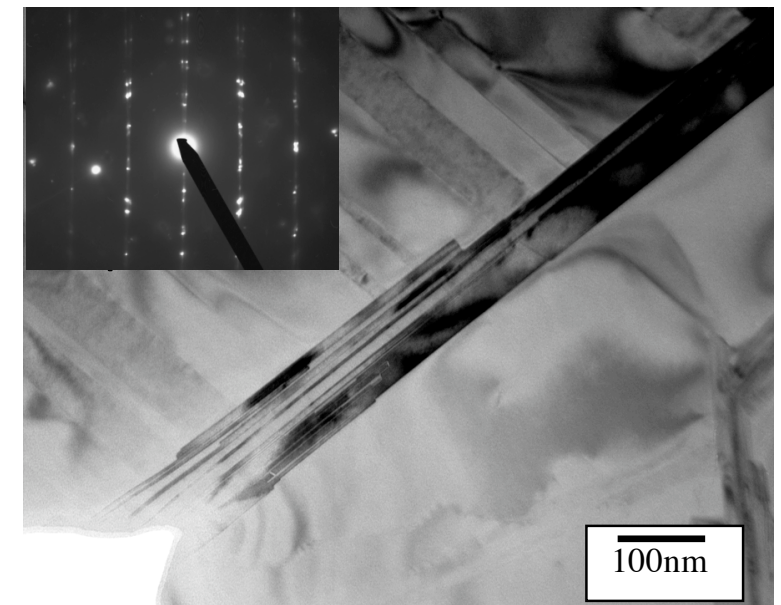

Figure 2 BF-TEM image of a ribbon consisting of thin boride and metal layers. The inset SADP shows the orientation relationships of the phases.
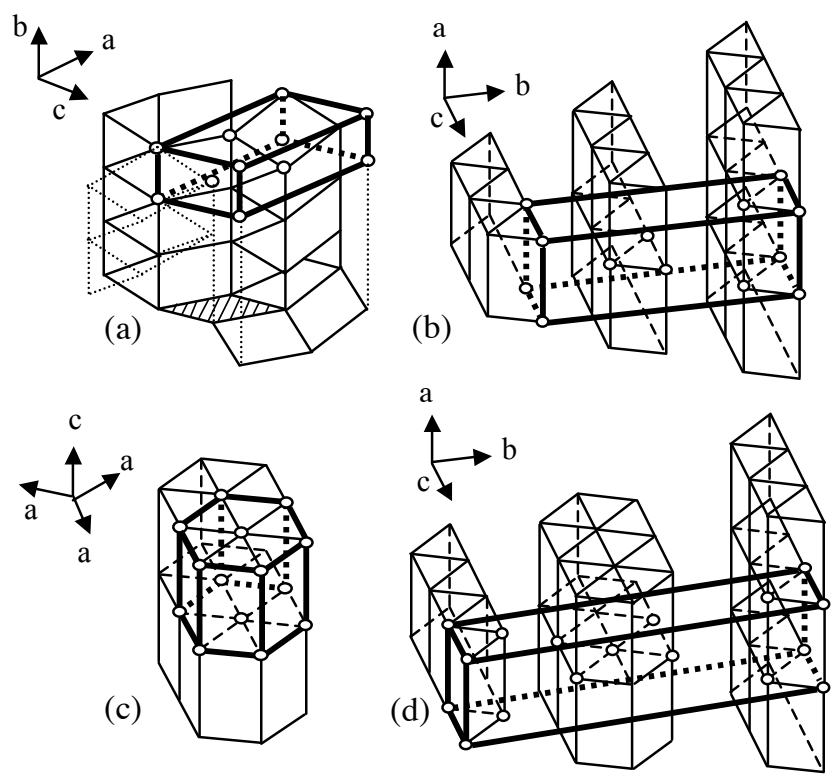

Figure 4 Schematic diagrams of the structures for the boride phases: (a) TiB-B27, (b) TiB-B (c) $\mathrm{TiB}_{2}$ and (d) $\mathrm{Ti}_{3} \mathrm{~B}_{4}$. 